\title{
Effects of intravenous diclofenac on postoperative sore throat in patients undergoing laparoscopic surgery at Aga Khan University Hospital, Nairobi: A prospective, randomized, double blind controlled trial
}

\author{
Thang’a P, Kamya D, *Mung'ayi V \\ Department of Anaesthesia, Agakhan University, East Africa
}

\begin{abstract}
Background: postoperative sore throat is the commonest complication after endotracheal intubation. The efficacy of intravenous non-steroidal anti-inflammatory drugs in alleviating postoperative sore throat has not been investigated.

Objective: To evaluate the effect of intravenous diclofenac sodium on the occurrence and severity of postoperative sore throat.

Methods: 42 in-patients scheduled for laparoscopic surgery were randomized into two equal groups to receive either a single dose of $75 \mathrm{mg}$ intravenous diclofenac sodium in addition to standard treatment taken at our hospital for the prevention of postoperative sore throat or to receive standard treatment only. All patients were interviewed postoperatively at 2, 6 and 18 hours. Data of the baseline characteristics, the incidence and severity of sore throat were collected. If sore throat was present, a Visual Analogue Score was used to assess its severity.

Results: the baseline characteristics of the participants were similar. The majority of the patients undergoing laparoscopic surgery were women. There was no statistically significant difference in the occurrence or severity of postoperative sore throat between the diclofenac and standard treatment groups at 2, 6 and 18 hours postoperatively.

Conclusion: Intravenous diclofenac sodium does not reduce the occurrence or severity of postoperative sore throat.

African Health Sciences 2013; 13(4): 999 - 1006 http://dx.doi.org/10.4314/ahs.v13i4.20
\end{abstract}

\section{Introduction}

Sore throat is a common, uncomfortable, distressing sequel of tracheal intubation that contributes to postoperative morbidity and patient dissatisfaction ${ }^{1-}$ ${ }^{6}$. The incidence of postoperative sore throat (POST) after tracheal intubation varies from 6.6 to $90 \% \%^{7-12}$. The pathogenesis of POST is attributed to traumatisation, local irritation and inflammation of the airway mucosa during tracheal intubation ${ }^{13-15}$.

Numerous non-pharmacological and pharmacological measures aimed at attenuating POST have been investigated with varying success. Among the non-pharmacological methods, a smaller sized endotracheal tube (ETT), lubricating the ETT with water soluble jelly, careful airway instrumentation, intubation after full relaxation, gentle oropharyngeal suctioning, minimizing intracuff pressure, and extubation when the tracheal tube cuff

\footnotetext{
*Corresponding author:

Dr Vitalis Mung'ayi

Department of Anaesthesia

Aga Khan University

East Africa

Phone: +254 203662157

Email: vitalis.mung’ayi@aku.edu
}

is fully deflated have been reported to decrease the incidence of POST ${ }^{12,13,16,17 .}$

Various pharmacological measures, including lignocaine, steroids, non-steroidal anti-inflammatory drugs, gargling with azulene sulfonate, have been reported to decrease the incidence of POST 1, 2, 9, 18, $19,39,40$.

Despite the inflammatory pathogenesis of POST, the evidence supporting the use of nonsteroidal anti-inflammatory drugs (NSAIDs) for POST is limited ${ }^{5,8,10}$. Topical diclofenac epolamine, a NSAID, has been shown to be effective in reducing the severity and incidence of POST ${ }^{10}$. However, the more readily available diclofenac sodium which has been found to be effective in the treatment of postoperative pain when used orally, rectally or intravenously $\mathrm{y}^{20-22}$ has not been evaluated for its effect on POST.

This study aimed to investigate the effect of intravenously administered diclofenac sodium on the occurrence and severity of POST. 


\section{Methods}

Written approval to conduct the study was sought and obtained from the Aga Khan University Research Ethics Committee (REC). Recruitment into this study was wholly voluntary and a participant could withdraw their consent at any time without any consequence to their routine care. Eligible patients were approached and received a consent-seeking information sheet. The investigator was also available to answer any further enquiries that arose. After full disclosure, eligible patients who agreed to participate in the study signed an informed consent form.

This is a prospective, randomized, controlled double blinded trial.

The study was conducted at Aga Khan University Hospital, Nairobi (AKUH, N). The AKUH, $\mathrm{N}$ is a 254-bed private not-for-profit institution that provides tertiary and secondary level health care services.

The study population consisted of all adult inpatients endotracheally intubated for laparoscopic surgery at the AKUH, N. This patient population was selected for this study because postoperative pain for both gynaecological and general surgery laparoscopic procedures is well controlled with pre-emptive infiltration of the surgical incision sites with local anaesthetic ${ }^{23-33}$, and with a combination of an opioid and paracetamol postoperatively $25,34,35$. This reduced the need for a NSAID postoperatively the administration of which would have confounded the results of this study.

All adult American Society of Anaesthesiologists (ASA) class 1-3 inpatients that would be intubated for laparoscopic surgery and had no contraindication to use of intravenous diclofenac were included. A sample size of 36 patients was sufficient to demonstrate a $49 \%$ difference in the occurrence of POST between patients who receive standard treatment at AKUH, $\mathrm{N}$ and those who received intravenous diclofenac. The study was powered at $90 \%$ with an alpha of 5\%. Previous studies showed 13.6\% occurrence of POST when topical diclofenac was used $^{10}$. There are no studies that look specifically at the composite effect of the standard treatment measures used at AKUH, $\mathrm{N}$ to prevent the occurrence of POST. Thus, for the calculation of sample size, a $63 \%$ occurrence of POST at AKUH, N was hypothesized from the study done by Edomwonyi et $\mathrm{al}^{7}$. Edomwonyi's study was chosen because it looked at the incidence of POST using standard treatment measures taken at Benin Teaching Hospital, it is the only published study done on the incidence of POST in Africa and the incidence of POST lies within the international $6.6-90 \%$ incidence of POST.
The sample size was increased by $15 \%$ to allow for drop out bringing the sample size to 42 patients, 21 patients in each arm. Simple randomisation was used in this study. Using a computer program, the statistician randomly assigned either drug or standard treatment to a list of 42 patients. This randomisation code handed over to a designated pharmacist.

Thirty minutes before the recruited patient's scheduled surgery, the investigator gave the designated pharmacist the study patient's unique hospital file number. Using the randomization code, the pharmacist then prepared the corresponding $200 \mathrm{ml}$ saline bag with or without diclofenac and labelled it with the patient's file number. The investigator collected the bag and delivered it to the anaesthetist assigned to the case. The intravenous diclofenac sodium available at AKUH, $\mathrm{N}$ comes as a $3 \mathrm{ml}$ colourless solution. To prevent precipitation when the diclofenac was added to normal saline, $0.5 \mathrm{ml}$ of $8.4 \%$ sodium bicarbonate-also a colourless liquid- was added to the mixture. Thus, the saline bags with diclofenac and those without contained colourless fluid indistinguishable from each other.

At the beginning of the study all consultant anaesthetists, anaesthesia resident doctors, anaesthetic assistants and nurses were familiarized with the scope of the study and tools of data collection and their cooperation sought. The $200 \mathrm{ml}$ saline infusion with or without diclofenac sodium was started just before induction of anaesthesia and run over 30min. Patient anaesthesia was induced and maintained with the anaesthetist's choice of drugs.

Female patients were intubated with size $7.0 \mathrm{~mm} \pm 0.5$ internal diameter tubes and male patients with $7.5 \mathrm{~mm} \pm 0.5$ internal diameter tubes lubricated with water soluble $2 \%$ lignocaine gel. A Smiths Medical Portex ${ }^{\circledR}$ cuff manometer was used to measure cuff pressures and whenever necessary to deflate the cuffs to a pressure of d" $20 \mathrm{mmHg}^{11,17}$. Cuff pressures were measured every $30 \mathrm{~min}$ and adjusted accordingly ${ }^{8}$. Intraoperative pain management consisted of $0.5 \%$ bupivacaine infiltrated pre-emptively into the port sites at a dose of $1-2 \mathrm{mg} / \mathrm{kg}^{28,36-38}$, Intramuscular morphine $10 \mathrm{mg}$ or Pethidine $75 \mathrm{mg}$ according to the anaesthetist's preference and intravenous paracetamol $1 \mathrm{~g}$.

Postoperative pain management for the first $24 \mathrm{hrs}$ consisted of intravenous paracetamol $1 \mathrm{~g}$ 6hourly and Intramuscular morphine $10 \mathrm{mg}$ 4-6hourly or intramuscular Pethidine $75 \mathrm{mg}$ 6hourly.

Patients in either arm who developed POST would be treated according to severity of sore throat.

Those with mild POST would be treated with throat lozenges every 2-3 hours $^{41}$.

Those with moderate to severe POST would be treated with ketamine $40 \mathrm{mg}$ in $30 \mathrm{ml}$ saline gargle ${ }^{23}$. 
If patients had surgical site pain despite prescribed analgesics they would have oral, rectal or intramuscular diclofenac sodium added to their postoperative analgesia and be dropped out of the study. None of the patients required rescue diclofenac during the study period, thus none were dropped out. Intraoperative data were collected by trained anaesthetic assistants using a data collection form.

Data on the presence or absence of POST and its severity were collected by the principal investigator using a structured questionnaire at 2, 6 and 18 hours postoperatively. Severity of POST was graded using a visual analogue scale, (VAS). The VAS has been found to have both validity and reproducibility for the measurement of postoperative pain and acute pain ${ }^{42-45}$. This questionnaire was pretested on 20 regular postoperative inpatients that had been intubated for surgery. No revisions were necessary.

All verified raw data were coded and entered into the Statistical Package for Social Sciences (SPSS) program, version 11.5 ( SPSS Inc. Chicago, IL, USA). Data analysis was performed using the same software.

Categorical data was summarised using a table and proportions were indicated. All count variables were summarised using median and continuous variables summarised using mean.

Difference in the occurrence of POST were analysed using Fischer's exact test and Pearson Chi square test. Severity of POST was analysed using the Mann Whitney $\mathrm{U}$ - test.

A $p$ value of $<0.05$ was considered statistically significant.

\section{Results}

Data collection was carried out over three and a half months-between January 2011 and April 2011. A total of 42 participants were recruited, almost entirely from the surgical wards, and randomised for the study. Two participants, one allocated to diclofenac and the other to standard treatment arm, were dropped out of the study after randomisation and were excluded from analysis. The former was admitted to the intensive care unit for ventilation, and the latter's surgery was converted from a laparoscopy to a laparotomy. Consequently, forty participants were included in the data analysis, twenty in each arm.

Baseline characteristics of patients in the two arms of the study were similar (table 1).

Table 1: Patient characteristics

\begin{tabular}{lll}
\hline & Diclofenac $\mathbf{n}=\mathbf{2 0}$ & Standard treatment $\mathbf{n}=\mathbf{2 0}$ \\
\hline Age(years) & $37.5 \pm 9.2$ & $36.5 \pm 5.9$ \\
ASA & $1(1,2)$ & $1(1,2)$ \\
Gender & & \\
Male & $3(75)$ & $1(25)$ \\
Female & $17(47.2)$ & $19(52.8)$ \\
Surgical procedure & & \\
Elective surgery & $20(51.3)$ & $19(48.7)$ \\
Emergency surgery & 0 & $1(100)$ \\
Tube size & & $3(50)$ \\
6.5 & $3(50)$ & $16(53.3)$ \\
7.0 & $14(46.7)$ & $1(25)$ \\
7.5 & $3(75)$ & $2(66.7)$ \\
Anaesthetists level of experience & & $4(66.7)$ \\
PGY1 & $1(33.3)$ & $5(41.7)$ \\
PGY 2 & $2(33.3)$ & 0 \\
PGY4 & $7(58.3)$ & $9(50)$ \\
Registrar & $1(100)$ & \\
Consultant & $9(50)$ & $16(50)$ \\
Number of intubation attempts & & $2(50)$ \\
1 & $16(50)$ & $2(50)$ \\
2 & $2(50)$ & $11(47.8)$ \\
3 & $2(50)$ & $10(50)$ \\
Cricoid pressure given & $12(52.2)$ & $7(70)$ \\
Use of nitrous oxide & $10(50)$ & $5.3)$ \\
Pharyngeal trauma & $1(16.7)$ & \\
Duration of surgery(min) & $114 \pm 51.2$ & \\
NG tube inserted & $3(30)$ & \\
Note: & 296 \\
\hline
\end{tabular}

Note: Mean age and duration of surgery are presented as mean \pm SD; ASA is presented as median (min, max); All other variables are presented as $n(\%)$ PGY- postgraduate year of training NG-nasogastric tube 
There was less POST in the diclofenac group compared to the standard treatment group at 2 and 6 hours but this did not reach statistical significance.
At 18 hours, the occurrence of POST was similar in the two groups

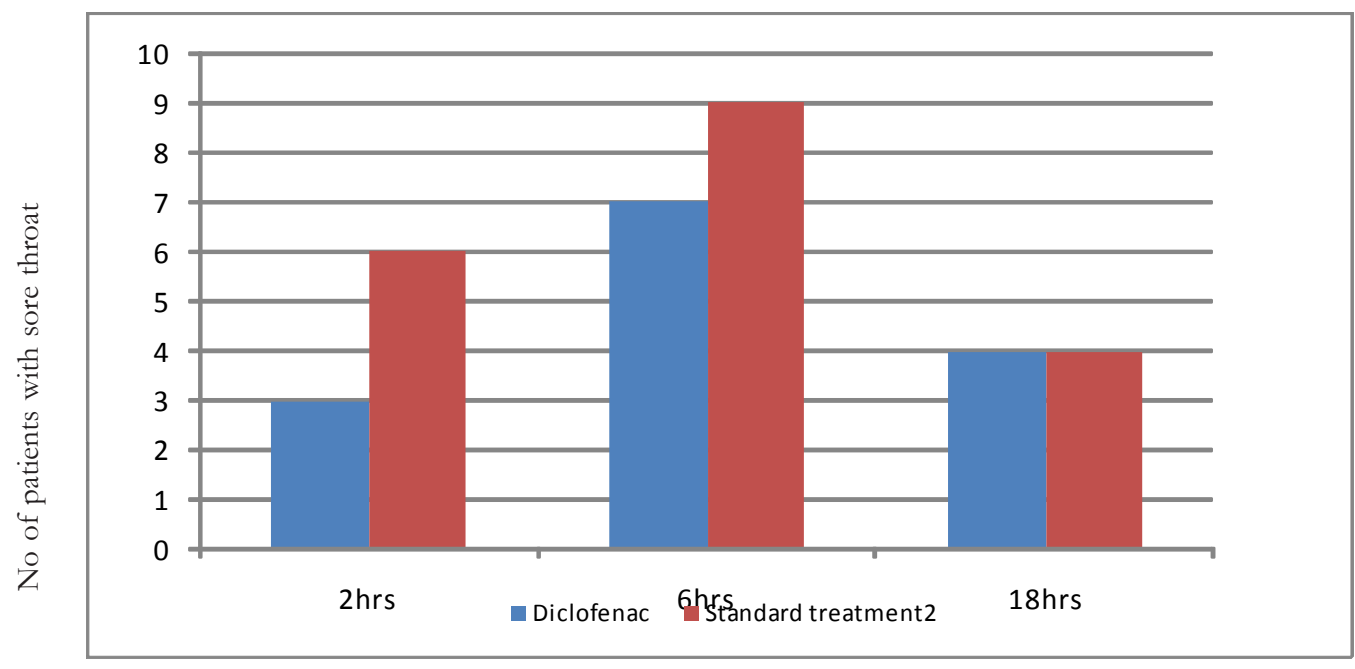

Figure 1: Occurrence of POST

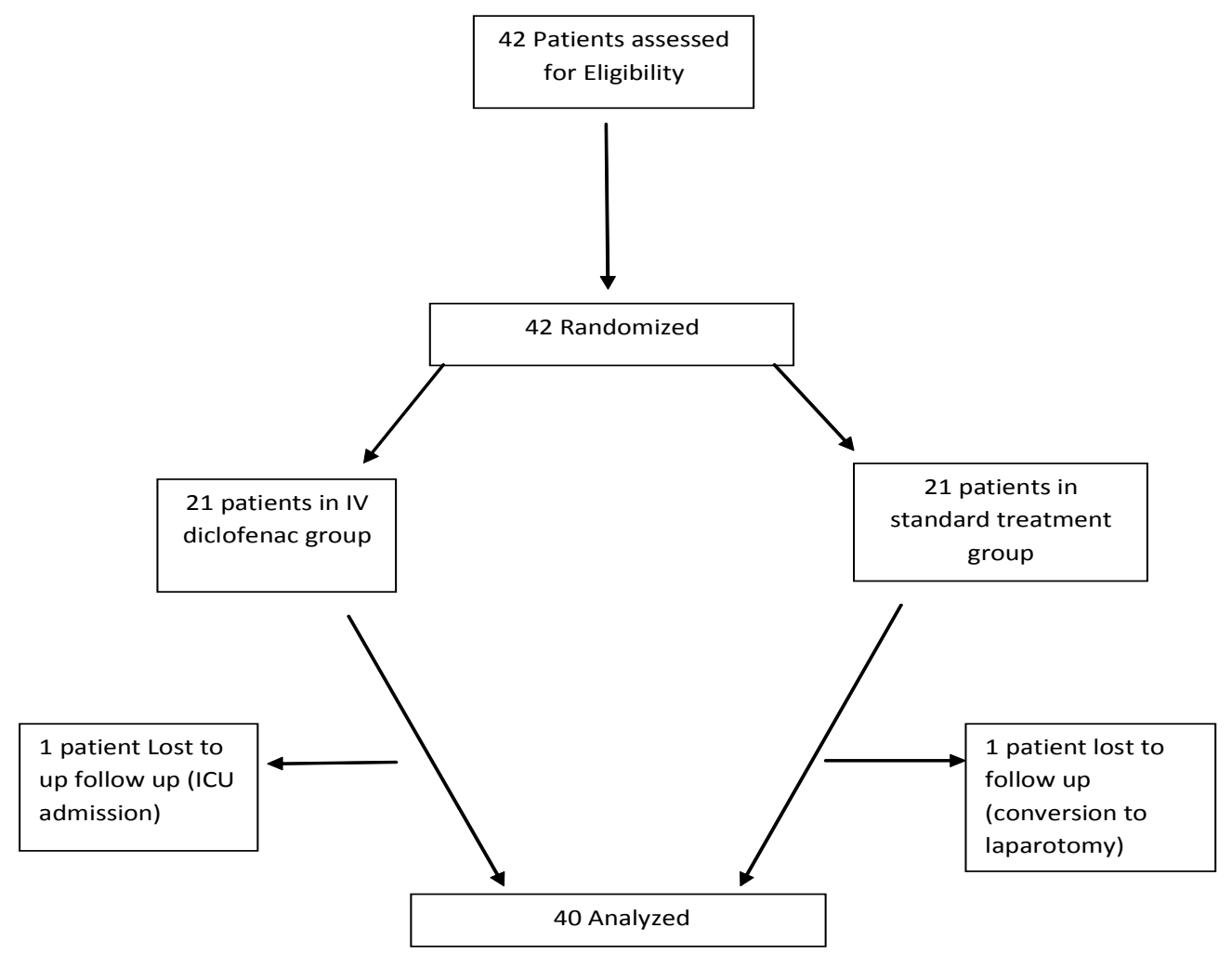

Figure 2. Flow diagram of patient distribution 
The difference in the median VAS score between the diclofenac and standard treatment groups at 2, 6 , and $18 \mathrm{hrs}$ was not statistically significant as shown table 2 .

At all study time points patients were asked whether their throats felt normal and if they did not, the patient was asked to describe the pharyngeal discomfort in their own words. Taking the total sample size as the denominator, the proportion of patients who experienced some degree of discomfort was $92 \%, 65 \%$ and $37.5 \%$ at 2,6 and 18 hours respectively. Frequency of the main terms used to describe the pharyngeal discomfort is shown in table 3 . in order of increasing severity from dry to no voice.

Table 2: Severity of POST

\begin{tabular}{llll}
\hline & Diclofenac & $\begin{array}{l}\text { Standard } \\
\text { treatment }\end{array}$ & p value \\
\hline VAS score at 2 hours & $0(0,5)$ & $0(0,5)$ & 0.361 \\
VAS score at 6 hours & $0(0,6)$ & $0(0,4)$ & 0.678 \\
VAS score at 18 hours & $0(0,4)$ & $0(0,3)$ & 0.862 \\
\hline
\end{tabular}

Note: VAS is presented as median (min, max)

Table 3: Patient's description of pharyngeal discomfort

\begin{tabular}{llll}
\hline & $\begin{array}{l}\text { No. of patients } \\
\text { at } 2 \text { hours }\end{array}$ & $\begin{array}{l}\text { No. of patients } \\
\text { at } 6 \text { hours }\end{array}$ & $\begin{array}{l}\text { No. of patients } \\
\text { at 18 hours }\end{array}$ \\
\hline Dry & 20 & 15 & 5 \\
Very Dry & 4 & 1 & 0 \\
Irritated/scratchy & 6 & 3 & 2 \\
Something stuck/blocked & 5 & 3 & 0 \\
No voice & 5 & 0 & 1 \\
\hline
\end{tabular}

\section{Discussion}

The pathogenesis of POST is attributed to trauma, local irritation and inflammation of the airway mucosa during tracheal intubation ${ }^{13-15}$. This tissue damage results in the release of prostaglandins which cause inflammation and pain ${ }^{20,40,41}$. Diclofenac sodium is a potent inhibitor of prostaglandin biosynthesis accounting for its pronounced antiinflammatory and analgesic properties ${ }^{41-43}$. This study was undertaken to investigate if this antiinflammatory and analgesic effect of diclofenac sodium would reduce the occurrence and severity of POST.

The major finding of this study is that a single $75 \mathrm{mg}$ dose of intravenous diclofenac sodium infused over 30 minutes at the induction of anaesthesia does not produce a statistically significant reduction in the occurrence or severity of POST. However, at 2 and 6 hours postoperatively, fewer patients in the diclofenac group had POST compared to the standard treatment group even if this difference was not statistically significant. By $18 \mathrm{hrs}$ the occurrence of POST was equal in both groups.
The reduced occurrence of POST at 2 and 6 hours may be explained by the pharmacokinetics of intravenous diclofenac. Once administered intravenously, diclofenac reaches its peak plasma concentration rapidly. The plasma concentration falls to half the peak value in 1.1 to $2 \mathrm{hrs}{ }^{44,45}$. Thus, the peak effect of intravenous diclofenac is in the first 2 hours after administration. From 5.5hrs after administration plasma concentration of diclofenac is below detection levels ${ }^{45}$ hence the reduction in activity.

A subjective assessment by the patient of how their throats felt postoperatively was sought. It was very interesting to note that at 2 hours $92 \%$ of patients had some degree of discomfort with or without a sore throat. This goes to show that, in the immediate postoperative period, some degree of throat discomfort will occur in almost all patients. This result has a number of implications on the anaesthesia process. First, the possibility of developing throat discomfort should be incorporated in the preoperative counselling of 
patients. Forewarning the patient would help reduce the number of factors causing patients' anxiety in the already stressful perioperative period. Second, this outcome emphasises the need to take all available pharmacological and non-pharmacological measures to reduce the risk of developing throat pain and discomfort post tracheal intubation. Third, the anaesthetist should ask the patient if they have throat pain or discomfort postoperatively and take the necessary measures to alleviate it.

There are only three prior studies investigating the use of NSAIDS to reduce the incidence and severity of POST. ${ }^{5,8,10}$ This study differs from these in two main ways. Firstly this study is the first to investigate the effect of an intravenous NSAID on POST. In all previous studies a topical preparation was administered. Secondly, none of the prior studies investigated diclofenac sodium.

In all previous studies, the local application of NSAIDs resulted in a statistically significant reduction in the incidence and/or severity of POST. Rahimi et al used a diclofenac epolamine patch applied to the anterior aspect of the neck, Ozaki et al, a ketoprofen patch also applied to the throat ${ }^{8}$ and Agarwal et al aspirin and benzydamine hydrochloride gargles ${ }^{5}$. The results from these studies imply that the anti-inflammatory action of NSAIDS is most effective with local application of NSAIDS The topical application of the NSAIDS in close proximity to the site of action or at the site of action may result in high drug concentrations in the pharyngeal mucosa. When diclofenac is administered intravenously, the bioavailability of the drug is $100 \%$. However, the concentration of drug achieved in the pharyngeal mucosa after intravenous administration has not been investigated. Thus, a difference in drug concentration at the pharyngeal mucosa may account for the topical agents producing decrease in the incidence and severity of POST. It would be interesting to conduct a study comparing the effect of a diclofenac sodium patch and other topical NSAID preparations on POST.

\section{Conclusion}

This study, in whom the majority of the participants were women, using a robust clinical design found that a single dose of intravenous diclofenac at the induction of anaesthesia does not reduce the occurrence or severity of POST.

\section{References}

1. Park SY, Kim SH, Lee AR, Cho SH, Chae WS, Jin HC, Lee JS, Kim YI. Prophylactic effect of dexamethasone in reducing postoperative sore throat. Korean J Anesthesiol, 2010; 58(1): 159.

2. Ayoub CM, Ghobashy A, Koch ME, McGrimley L, Pascale V, Qadir S, Ferneini EM, Silverman DG. Widespread application of topical steroids to decrease sore throat, hoarseness, and cough after tracheal intubation. Anesthesia Analgesia, 1998; 87(3): 714-6.

3. Christensen AM, Willemoes-Larsen H, Lundby L, Jakobsen KB. Postoperative throat complaints after tracheal intubation. BrJ Anaesth, 1994; 73(6): 786-7.

4. Mandoe HMN, Lone MD, Lintrup Uffe, Jepsen Dorte, Molgaard Jorgen MD. Sore Throat After Endotracheal Intubation. Anesthesia \& Analgesia. 1992; 74:, (6): 897-900.

5. Agarwal A, Nath SS, Goswami D, Gupta D, Dhiraaj S, Singh PK. An evaluation of the efficacy of aspirin and benzydamine hydrochloride gargle for attenuating postoperative sore throat: a prospective, randomized, single-blind study. Anesthesia Analgesia, 2006; 103(4): 1001-3.

6. Thomas S, Beevi S. Dexamethasone reduces the severity of postoperative sore throat. Can J Anaesth, 2007; 54(11): 897-901.

7. Edomwonyi NP. Postoperative Throat Complications after Tracheal Intubation. Annals of African Medicine, 2006; 5(1): 28 - 32.

8. Ozaki M, Minami K, Sata T, Shigematsu A. Transdermal ketoprofen mitigates the severity of postoperative sore throat : [Le ketoprofene transdermique reduit le mal de gorge postoperatoire]. Can J Anaesth, 2001; 48(11): 1080-3.

9. Tanaka Y, Nakayama T, Nishimori M, Sato Y, Furuya H. Lidocaine for preventing postoperative sore throat. Cochrane Database of Systematic Reviews 2009, Issue 3. Art. No.: CD004081. DOI: 10.1002/ 14651858.CD004081.pub2

10. Rahimi M, Makarem J. Effects of diclofenac epolamine patch on postoperative sore throat in parturients after cesarean delivery under endotracheal general anesthesia. Acta Anaesthesiol Taiwan, 2009; 47(1): 17-21. 
11. McHardy FE, Chung F. Postoperative sore throat: cause, prevention and treatment. Anaesthesia 1999; 54(5): 444-53.

12. Monroe MC, Gravenstein N, Saga-Rumley S. Postoperative Sore throat: effect of oropharyngeal airway. Anesthesia \& Analgesia., 1990; 70(5): 12-6.

13. Al-Qahtani AS, Messahel FM, Quality improvement in anesthetic practice-incidence of sore throat after using small tracheal tube. Middle East J Anesthesiol 2005; 18(1): 179-83.

14. Stout DM, Bishop MJ, Dwersteg JF, Cullen BF. Correlation of Endotracheal Tube Size with Sore Throat and Hoarseness Following General Anesthesia.Anesthesiology 1987; 67(3): 419-421.

15. Nordin U, Lindholm C E, Wolgast M. Blood flow in the rabbit tracheal mucosa under normal conditions and under the influence of tracheal intubation. Acta Anaesthesiol Scand 1977; 21(2): p. 81-94.

16. Lévy B, Mouillac F, Quilichini D, Schmitz J, Gaudart J, Gouin F. Topical methylprednisolone vs lidocaine for the prevention of postoperative sore throat. Ann Fr Anesth Reanim 2003; 22(7): 595-9.

17. Ogata J, Minami K, Horishita T, Shiraishi M, Okamoto T, Terada T, Sata T. Gargling with sodium azulene sulfonate reduces the postoperative sore throat after intubation of the trachea. Anesthesia Analgesia, 2005; 101(1): 290-3

18. Ku EC, Lee W, Kothari HV, Scholer DW. Effect of diclofenac sodium on the arachidonic acid cascade. Am J Med 1986; 80(4B): 18-23.

19. Willis JV, Kendall MJ, Flinn RM, Thornhill DP, Welling PG. The pharmacokinetics of diclofenac sodium following intravenous and oral administration. Eur J Clin Pharmacol 1979; 16(6): 405-10.

20. John VA. The pharmacokinetics and metabolism of diclofenac sodium (Voltarol) in animals and man. Rheumatol Rebabil 1979; Suppl 2: 22-37.

21. Barden J, Edwards J, Moore RA, McQuay HJ. Single dose oral diclofenac for postoperative pain. Cochrane Database Syst Rev 2004; 2: CD004768.

22. Derry P, Moore RA, McQuay HJ. Single dose oral diclofenac for acute postoperative pain in adults. Cochrane Database of Systematic Reviews 2009; (2 Art. No. CD004768. DOI: 10.1002/ 14651858.CD004768.pub2.).

23. Canbay O, Celebi N, Sahin A, Celiker V, Ozgen $\mathrm{S}$, Aypar U. Ketamine gargle for attenuating postoperative sore throat. $\mathrm{Br} J$ Anaesth, 2008; 100(4): 490-3.

24. Higgins PP, Chung F, Mezei G. Postoperative sore throat after ambulatory surgery. BrJ Anaesth, 2002; 88(4): 582-4.

25. Macario A, Weinger M, Carney S, Kim A. Which clinical anesthesia outcomes are important to avoid? The perspective of patients. Anesthesia Analgesia, 1999; 89: 652-8.

26. Bamgboye EA, Olubuyide IO, al-Shammari S. The rate of sickness absenteeism among employees at King Khalid University Hospital, Riyadh, Saudi Arabia. East Afr MedJ 1993; 70(8): 515-8.

27. Laffel G, Blumenthal D. The case for using industrial quality management science in health care organizations. JAMA 1989; 262(20): 286973.

28. Lohsiriwat V, Lert-akyamanee N, Rushatamukayanunt W. Efficacy of preincisional bupivacaine infiltration on postoperative pain relief after appendectomy: prospective double-blind randomized trial. World J Surg 2004; 28(10): 947-50.

29. Alessandri F, Lijoi D, Mistrangelo E, Nicoletti A, Ragni N. Effect of presurgical local infiltration of levobupivacaine in the surgical field on postsurgical wound pain in laparoscopic gynecological surgery. Acta Obstet Gynecol Scand, 2006; 85(7): 844-9.

30. Khaira H.S, Wolf J.SJr. Intraoperative local anesthesia decreases postoperative parenteral opioid requirements for transperitoneal laparoscopic renal and adrenal surgery: a randomized, double-blind, placebo controlled investigation. J Urol 2004; 172(4 Pt 1): 1422-6.

31. Goldstein A, Grimault P, Henique A, Keller M, Fortin A, Darai E. Preventing postoperative pain by local anesthetic instillation after laparoscopic gynecologic surgery: a placebocontrolled comparison of bupivacaine and ropivacaine. Anesthesia Analgesia 2000; 91(2): 4037.

32. Mraoviæ B, Jurisix T, Kogler-Majeric V, Sustic A. Intraperitoneal bupivacaine for analgesia after laparoscopic cholecystectomy. Acta Anaesthesiol Scand 1997. 41(2): 193-6.

33. Pasqualucci A, de Angelis V, Contardo R, Colò F, Terrosu G, Donini A, Pasetto A, Bresadola F. Preemptive analgesia: intraperitoneal local anesthetic in laparoscopic cholecystectomy. A 
randomized, double-blind, placebo-controlled study. Anesthesiology 1996. 85(1): 11-20.

34. Szem J.W, Hydo L, Barie P S. A double-blinded evaluation of intraperitoneal bupivacaine vs saline for the reduction of postoperative pain and nausea after laparoscopic cholecystectomy. Surg Endosc 1996; 10(1): 44-8.

35. Joris J, Thiry E, Paris P, Weerts J, Lamy M. Pain after laparoscopic cholecystectomy: characteristics and effect of intraperitoneal bupivacaine. Anesthesia Analgesia 1995; 81(2): 37984.

36. Scheinin B, Kellokumpu I, Lindgren L, Haglund C, Rosenberg PH. Effect of intraperitoneal bupivacaine on pain after laparoscopic cholecystectomy. Acta Anaesthesiol Scand 1995; 39(2): 195-8.

37. Chundrigar T, Hedges AR, Morris R, Stamatakis JD. Intraperitoneal bupivacaine for effective pain relief after laparoscopic cholecystectomy. Ann R Coll Surg Engl 1993; 75(6): 437-9.

38. Ng A, Swami A, Smith G, Davidson AC, Emembolu J. The analgesic effects of intraperitoneal and incisional bupivacaine with epinephrine after total abdominal hysterectomy. Anesthesia Analgesia 2002; 95(1): 158-6.

39. Lahtinen P, Kokki H, Hendolin H, Hakala T, Hynynen M. Propacetamol as adjunctive treatment for postoperative pain after cardiac surgery. Anesthesia Analgesia 2002; 95(4): 813-9.

40. Memis D, Inal MT, Kavalci G, Sezer A, Sut N. Intravenous paracetamol reduced the use of opioids, extubation time, and opioid-related adverse effects after major surgery in intensive care unit. J Crit Care. 2010; 25(3): 458-62.

41. Ebneshahidi, A, Mohseni M. Strepsils(R) tablets reduce sore throat and hoarseness after tracheal intubation. Anesthesia Analgesia. 2010;111(4): 8924.

42. Berthier F, Potel G, Leconte P, Touze MD, Baron D. Comparative study of methods of measuring acute pain intensity in an ED. Am J Emerg Med 1998; 16(2): 132-6.

43. Bijur P.E, Latimer C T, Gallagher E J. Validation of a verbally administered numerical rating scale of acute pain for use in the emergency department. Acad Emerg Med 2003; 10(4): 3902.

44. Breivik E.K, Bjornsson G A, Skovlund E. A comparison of pain rating scales by sampling from clinical trial data. Clin J Pain 2000; 16(1): 22-8.

45. Kremer E, Atkinson J H, Ignelzi R J. Measurement of pain: patient preference does not confound pain measurement. Pain 1981; 10(2): 241-8. 